\title{
INTERAKSI INSTRUCTIONAL MODEL DAN ENTRY LEVEL TERHADAP MISKONSEPSI MAHASISWA
}

\author{
I Ketut Suandi ${ }^{1)}$, Cening Ardina ${ }^{2)}$, dan I Ketut Parnata ${ }^{3)}$ \\ 1), 2), 3) Jurusan Akuntansi, Politeknik Negeri Bali, Bukit Jimbaran, Badung, 80364 \\ E-mail: ${ }^{1)}$ wandisakura@gmail.com
}

\begin{abstract}
Learners have different entry level and have varying misconception. Misconception of learners tend to be resistant and difficult to change. Alternative instructional model need to be developed to reduce students' misconception. The purposes of this study are: (1) to describe of students' misconception profile in accounting subjects, (2) to describe the stages of reducing students' misconception, and (3) to analyze the interaction effect between instructional model and entry level to the students' misconception. This quasi experimental study uses two-factor measurement with a factorial version of nonequivalent pretest-postest control group design. The Variables in this study are: students' misconception, instructional model, and entry level. The total samples are 203 students and each treatment decided 29 subjects as analysis unit. Base on the analysis, the results of the study are: (1) The students' misconception profile varies and occur in the cost concept, entity business concept, and matching concept. (2) The stages of reducing students' misconception starting from orientation, elicitation, restructuration, application, and review. (3) There is a significant interaction effect between instructional model and entry level to students' misconceptions. It is suggested that, cooperative instructional model based on entry level can be applied to reduce students' misconception.
\end{abstract}

Keywords: entry level, misconception, conventional, elicitation, cooperative

\begin{abstract}
Abstrak
Peserta didik memiliki entry level yang berbeda dan memiliki miskonsepsi yang bervariasi. Miskonsepsi peserta didik cenderung resisten dan sulit berubah. Model pembelajaran alternatif perlu dikembangkan untuk mereduksi miskonsepsi mahasiswa. Penelitian ini bertujuan: (1) mendeskripsikan profil miskonsepsi mahasiswa dalam pembelajaran akuntansi, (2) mendeskripsikan tahapan mereduksi miskonsepsi mahasiswa, dan (3) menganalisis pengaruh interaktif antara instructional model dan entry level terhadap miskonsepsi mahasiswa. Penelitian kuasi eksperimen ini menggunakan pengukuran dua faktor dengan versi faktorial nonequivalent pretest-posttest control group design. Variabel dalam penelitian ini adalah: miskonsepsi, instructional model, dan entry level. Total sampel yang digunakan sebanyak 203 orang mahasiswa dan masing-masing perlakuan ditetapkan 29 subjek sebagai unit analisis. Berdasarkan hasil analisis, ditemukan hasil-hasil penelitian sebagai berikut: (1) Profil miskonsepsi mahasiswa bervariasi dan terjadi pada konsep harga perolehan, konsep kesatuan usaha, dan konsep mempertemukan. (2) Tahapan mereduksi miskonsepsi mahasiswa mulai dari tahapan orientasi, elicitasi, restrukturisasi, aplikasi, dan review. (3) Terdapat pengaruh interaktif antara instructional model dan entry level terhadap miskonsepsi mahasiswa. Disarankan, model pembelajaran kooperatif berbasis entry level bisa diterapkan untuk mereduksi miskonsepsi peserta didik..
\end{abstract}

Kata kunci: entry level, miskonsepsi, konvensional, elicitasi, kooperatif 


\section{PENDAHULUAN}

Peran pendidik untuk mengatur, menyiapkan, dan membantu peserta didik dalam proses pembelajaran merupakan paradigma baru dalam pendidikan. Konsekuensinya, peran pendidik bergeser sebagai fasilitator, motivator, dan mediator pembelajaran. Kondisi saat ini menunjukkan bahwa, kemasan pembelarannya masih menitikberatkan pada peran peserta didik dan pendidik masih memegang otoritas. Kemasan pembelajaran seperti itu mengakibatkan terciptanya pemahaman konsep bagi mahasiswa yang bersifat temporary. Pemahaman konsep dalam bidang akuntansi berjenjang, mulai dari tingkat dasar sampai dengan tingkat tinggi. Mengingat jenjang dan tahapan pembelajaran akuntansi seperti itu, maka pemahaman konsep-konsep menjadi tujuan utama dalam pembelajaran akuntansi. Pada tingkat dasar, proses pemahaman konsep sudah dimulai dari tahapan recording sampai dengan reporting. Hal ini berarti pada pembelajaran akuntansi tingkat dasar telah tertanam konsep-konsep yang harus dipahami mahasiswa secara tuntas. Pemahaman konsep seorang peserta didik sangat tergantung dari kemasan pembelajaran yang diterapkan pendidik.

Secara umum tujuan pembelajaran akuntansi adalah, mahasiswa diharapkan mampu menghasilkan informasi keuangan yang wajar untuk disampaikan kepada pihak users sebagai dasar pengambilan keputusan entitas bisnis. Namun demikian, dalam upaya mencapai tujuan pembelajaran umum tersebut, hingga saat ini belum ada bahan ajar yang relevan untuk mendukung proses pembelajaran. Bahan-bahan pembelajaran hanya terbatas pada contoh-contoh yang sederhana dan kemasannya kurang representatif sebagai supporting material dalam pemahaman konsep. Padahal, realitanya pembelajaran akuntansi pada setiap jenjang dipenuhi oleh konsep-konsep yang harus dipahami dengan utuh oleh peserta didik agar memperoleh ketuntasan belajar yang lebih cepat. Proses transform pemahaman kepada peserta didik tidak bisa dilakukan secara seragam dan serentak, mengingat kemampuan peserta didik sangat bervariasi terutama dalam mengkemas pembelajaran pada semester awal.

Peserta didik pembelajaran akuntansi sangat heterogen yang mencerminkan entry level tentang akuntansi sangat berbeda secara signifikan. Peserta didik yang telah memiliki latar belakang akuntansi hanya 13,15\%. Sedangkan sisanya, sebesar $86,85 \%$ belum bahkan tidak memiliki entry level atau pengetahuan awal yang memadai. Pengukuran pengetahuan awal tidak hanya berfungsi sebagai suatu prediktor belajar yang tepat, tetapi juga menyediakan dasar yang lebih bermanfaat dalam pembelajaran (Santyasa, 2004). Konsekuensi logis dari kondisi awal tersebut, kemasan pembelajaran sangat menentukan pemahaman konsep dalam pembelajaran. Situasi belajar harus terhindar dari suasana kompetitif terutama bagi peserta didik yang memiliki entry level belum memadai.

Sampai saat ini pembelajaran sebagian besar masih dikemas secara konvensional, dan masih dinominasi oleh kegiatan pendidik. Pembelajaran semacam ini cenderung membuat mahasiswa menjadi pasif. Upaya ke arah perbaikan kualitas pembelajaran telah dilakukan, namun hasilnya belum optimal. Hal ini menandakan bahwa ada masalah dengan proses pembelajaran yang sedang diimplementasikan. Berkaitan dengan proses pembelajaran akuntansi, terdapat beberapa permasalahan seperti: (a) pemahaman konsep mahasiswa belum tuntas, (b) kreatifitas dan aktivitas belajar mahasiswa masih rendah, dan (c) para pendidik belum memperhatikan entry level yang melekat pada diri peserta didik. 
Pemahaman konsep yang memadai menjadi persyaratan mutlak dalam pembelajaran akuntansi. Rendahnya kreatifitas dan aktivitas belajar mahasiswa adalah akibat dari kemasan pembelajaran secara konvensional. Entry level memiliki peranan yang sangat penting dalam proses pembelajaran dan memiliki posisi yang strategis. Entry level menjadi perhatian dan pertimbangan para praktisi dan teoretisi pembelajaran dalam mengkemas pembelajaran dalam upaya meremidiasi miskonsepsi peserta didik yang cenderung resisten. Brook \& Brook (1993) mengatakan bahwa, manusia mencoba mengerti dunianya dengan mensintesis pengalaman baru ke dalam pengetahuan yang telah dipahami sebelumnya. Faktor terpenting yang mempengaruhi belajar, adalah apa yang telah diketahui peserta didik. Muhittin Caliskan (2014) menjelaskan lebih spesifik tentang pentingnya kemampuan awal, "cognitive entry behaviors are a form of prelearning that is required in order to learn a specific learning unit”. Beberapa penelitian tentang effect of pre-learning telah dilakukan (Hailikari, Nevgi, \& Kamulainen, 2008; Thompson \& Zamboanga, 2004). Hasil penelitian menunjukkan bahwa pre-learning merupakan variable kunci dalam menentukan level pembelajaran.

Proses belajar mengajar yang sedang diterapkan masih menitikberatkan pada rote learning concept. Iklim pembelajaran semacam ini sangat merugikan peserta didik yang kemampuan akademisnya rendah. Peserta didik yang kurang mampu, suasana kompetitif sangat mengurangi motivasi belajarnya dan senantiasa menjadi siksaan psikologis mereka (Slavin, 1995). Oleh sebab itu, para pendidik perlu menciptakan suasana kelas yang penuh toleransi dan menyenangkan. Suasana pembelajaran yang menyenangkan dan jauh dari suasana kompetitif dapat tercipta melalui rancangan pembelajaran yang kolaboratif. Salah satu kemasan pembelajaran yang memiliki aspek kolaborasi adalah kemasan pembelajaran yang diseting dengan cooperative learning. Seting pembelajaran ini dapat menyediakan peluang bagi mahasiswa untuk dapat memahami konsep ilmiah dengan baik dan tuntas. Pemahaman suatu konsep yang keliru (misconception) cenderung sulit untuk diubah. Miskonsepsi dapat terjadi dari pengalaman belajar sebelumnya. Miskonsepsi didefinisikan sebagai kesalahan pemahaman yang mungkin terjadi selama atau sebagai hasil dari pengajaran yang baru saja diberikan, berlawanan dengan konsepsi-konsepsi ilmiah yang dibawa atau berkembang dalam waktu lama (Mosik, 2010).

Berdasarkan hal tersebut, maka salah satu strategi yang dapat ditempuh guna meremidiasi miskonsepsi adalah dengan melakukan redesain pembelajaran dari model pembelajaran yang biasa diterapkan menuju desain yang lebih kolaboratif dan penuh makna (meaningfull learning concept). Dengan demikian, cooperative learning dipilih sebagai suatu studi eksperimental dalam upaya untuk meremidiasi miskonsepsi mahasiswa dengan memperhatikan entry level peserta didik. Seting pembelajaran ini diharapkan mampu memfasilitasi mahasiswa untuk mengurangi miskonsepsi dalam pembelajaran akuntansi. Pembelajaran akuntansi yang menekankan pada pemahaman konsep secara utuh dan tuntas sangat memungkinkan diterapkan di Satuan Pendidikan Vokasi Politeknik dengan dukungan sumber daya pendidikan yang memadai. Berdasarkan permasalahan yang telah terindentifikasi, maka rumusan masalah dalam penelitian ini adalah: (1) bagaimanakah profil miskonsepsi peserta didik dalam mengikuti pembelajaran akuntansi, (2) bagaimanakah tahapan mereduksi miskonsepsi yang melekat pada diri mahasiswa, dan (3) apakah terdapat pengaruh interaktif antara instructional model dan entry level terhadap miskonsepsi mahasiswa dalam 
pembelajaran akuntansi. Tujuan penelitian ini adalah: (1) mendeskripsikan profil miskonsepsi peserta didik dalam mengikuti pembelajaran akuntansi, (2) mendeskripsikan tahapan mereduksi miskonsepsi yang melekat pada diri mahasiswa, dan (3) menganalisis pengaruh interaktif antara instructional model dengan entry level terhadap miskonsepsi peserta didik dalam pembelajaran Akuntansi.

\section{METODE PENELITIAN}

Peneliti menggunakan metode penelitian eksperimen dengan design penelitian Nonequivalent Control Group Design. Rancangan analisis penelilian ini adalah faktorial $2 \times 2$. Faktor pemilahnya adalah variabe1 moderator entry level mahasiswa. Pemilahan dibagi menjadi dua level yaitu entry level di atas rata-rata kelompok (50\% dari atas) dan di bawah rata-rata kelompok (50\% dari bawah). Penentuan sampel dalam penelitian ini menggunakan jenis probability sampling dengan menggunakan teknik sampling cluster. Metode pengumpulan data yang digunakan adalah dengan pemberian tes kepada sampel penelitian untuk mendapatkan data tentang entry level dan miskonsepsi. Variabel terikat adalah keluaran yang terjadi karena pengaruh variabel bebas dan variabel moderator, yaitu miskonsepsi peserta didik. Variabel bebas dalam penelitian ini adalah faktor yang sengaja dimunculkan dan diukur nilainya, yaitu instructional model yang terdiri dari dua dimensi, yaitu cooperative learning dan conventional. Variabel moderator dalam penelitian ini adalah entry level yang terdiri dari dua dimensi, yaitu high entry level dan low entry level. Entry level dalam penelitian ini adalah pengetahuan atau seperangkat informasi yang telah dimiliki peserta didik berkaitan dengan materi-materi pembelajaran yang dibahas oleh pendidik secara formal di dalam kelas. Entry level yang melekat pada diri mahasiswa tersebut diukur dengan melakukan tes entry level, dan data yang diperoleh adalah data interval. Secara kuantitatif, entry level adalah skor yang dicapai mahasiswa yang tertuang dalam butir tes. Konsep awal atau konsepsi yang tidak sesuai dengan konsep ilmiah biasa disebut miskonsepsi. Miskonsepsi merujuk pada suatu konsep yang tidak sesuai dengan pengertian ilmiah atau pengertian yang diterima para pakar dalam bidang tersebut. Miskonsepsi dapat berbentuk konsep awal, kesalahan hubungan yang tidak benar antara konsepkonsep, gagasan intuitif atau pandangan yang salah. Miskonsepsi sering terjadi pada peserta didik mulai dari pendidikan dasar sampai dengan pendidikan tinggi. Miskonsepsi merupakan suatu interpretasi konsep-konsep dalam suatu pernyataan yang tidak dapat diterima atau penjelasan yang salah dan suatu gagasan yang tidak sesuai dengan pengertian ilmiah yang diterima.

Teknik analisis data dalam penelitian ini menggunakan statistik deskriptif dan analisis faktorial $2 \times 2$. Analisis deskriptif digunakan untuk mendeskripsikan miskonsepsi peserta didik. Analisis data dengan menggunakan Anava dua-jalur, ada dua asumsi yang harus dipenuhi, yaitu: (1) setiap skor dalam sel harus berdistribusi normal, dan (2) variansi skor pada setiap sel harus homogen atau sama. Berdasarkan asumsi tersebut, maka perlu dilakukan uji normalitas dan homogenitas. Untuk menguji normalitas data digunakan statistik kolmogorov-Smirnov Test dan Shapiro-Wilks Test (Santoso, 2003). Jika angka signifikansi yang dihasilkan lebih dari 0,05, maka sebaran frekuensi skor variabel tersebut adalah normal. Untuk menguji homogenitas varians antar kelompok digunakan Levene's Test of Equality of Error Variance (Santoso, 2003). Kriteria pengujian adalah varians dikatakan homogen jika angka signifikansi yang dihasilkan lebih besar dari 0,05. 


\section{HASIL DAN PEMBAHASAN}

Profil miskonsepsi peserta didik diidentifikasi melalui pemberian tes awal (pretest) kepada mahasiswa. Profil miskonsepsi yang ada pada diri mahasiswa sehubungan dengan konsepkonsep dalam pembelajaran akuntansi mencakup beberapa konsep antara lain, konsep kesatuan usaha, konsep harga perolehan, dan konsep pencocokan. Konsep kesatuan usaha (entity business concept) merupakan konsep yang mendasar dalam proses pencatatan. Konsep ini sebagai dasar terbentuknya persamaan akuntansi yang tidak bisa diubah secara matematis. Konsep persamaan tersebut adalah "hak" harus sama dengan "kewajiban”, "sumber" harus sama dengan "penggunaan", "darimana" harus sama dengan "untuk apa”. Pemilik dan creditur memiliki status yang sama sebagai pihak eksternal. Peserta didik yang memiliki konsep ilmiah tentang konsep kesatuan usaha rata-rata sebesar $31 \%$, sebesar $69 \%$ masih mengalami miskonsepsi. Konsep harga perolehan (cost concept) merupakan konsep yang menjadi dasar dalam penilaian aset yang dimiliki perusahaan untuk disajikan dalam laporan keuangan. Peserta didik yang memiliki konsep ilmiah tentang konsep harga perolehan (cost) rata-rata sebesar 41\%, sebesar 59\% masih mengalami miskonsepsi. Pengeluaran-pengelauaran yang terjadi dalam memperoleh aset sampai aset tersebut siap digunakan harus diperhitungkan. Aset dicatat sebesar pengeluaran kas (atau setara kas) yang dibayar atau sebesar nilai wajar dari imbalan yang diberikan untuk memperoleh nilai tersebut pada saat perolehan (IAI, 2012). Harga pasar tidak bisa menjadi acuan dalam penilaian aset karena sangat dinamis dan cepat berubah. Konsep pencocokan adalah konsep mempertemukan pendapatan dengan beban dalam periode yang sama. Beban diakui dalam laporan laba rugi atas dasar hubungan langsung antara biaya yang timbul dan pos penghasilan tertentu yang diperoleh (IAI, 2012). Peserta didik yang memiliki konsep ilmiah tentang konsep mempertemukan (matching) rata-rata sebesar 36\%, dan sisanya masih mengalami miskonsepsi.

Driver dan Oldham (dalam Suparno, 1997), beberapa tahapan mengajar berbasis cooperative-konstruktivis adalah: orientasi, elicitasi, restrukturisasai ide, penggunaan Ide dalam banyak situasi, dan review. Tahapan dari orientasi sampai dengan review sangat membantu pendidik dalam mereduksi miskonsepsi yang melekat pada diri peserta didik.

Tahapan orientasi, pebelajar diberi kesempatan untuk mengembangkan motivasi dalam mempelajari suatu topik dan diberi kesempatan untuk mengadakan observasi terhadap topik yang hendak dipelajari. Tujuannya, agar peserta didik memperoleh akademik atmosfir yang kondusif. Tahapan elicitasi, mahasiswa dibantu untuk mengungkapkan idenya secara jelas dengan berbagai cara (berdiskusi, menulis, dan lain-lain). Dalam model pembelajaran ini, pebelajar mengklarifikasi ide, merombak ide dengan melakukan konflik terhadap situasi yang berlawanan, mengkonstruksi, dan mengevaluasi ide yang baru. Tahapan orientasi dan elicitasi dilakukan untuk menciptakan situasi pembelajaran yang kondusif, mengasyikkan, membangkitkan minat belajar, dan mengemukakan gagasan intuitifnya sehingga tahapan refleksi dapat dilakukan. Tahapan Restrukturisasi ide yang dilakukan dengan memberi tantangan, menciptakan konflik kognitif, dan membangun ulang kerangka konseptual sehingga mahasiswa mampu mengaplikasikan konsepnya dalam banyak situasi. Menciptakan konflik kognitif sangat efektif untuk merubah miskonsepsi peserta didik. Mosik (2010) melakukan penelitian yang menyatakan bahwa, pendekatan konflik kognitif dalam pembelajaran fisika mempunyai pengaruh yang signifikan terhadap miskonsepsi 
fisika. Pernyataan tersebut diperkuat oleh Kwon (2006) yang menyatakan bahwa, pengaruh konflik kognitif dengan metode demonstrasi menunjukan terjadinya perubahan pemahaman konsep pada siswa tentang fisika yang lebih efektif dibandingkan dengan metode yang lain. Pendekatan konflik kognitif memerlukan beberapa tahapan dalam upaya untuk membangun ulang kerangka konseptual peserta didik. Menurut Lee (2003), proses konflik kognitif meliputi tiga tahap yaitu: (1) Pendahuluan (preliminary), (2) konflik (conflict), dan (3) penyelesaian (solution) yaitu kegiatan diskusi dan menyimpulkan hasil diskusi.

Sedangkan tahapan review dilakukan untuk meninjau keberhasilan model pembelajaran yang telah berlangsung dalam upaya mereduksi miskonsepsi yang muncul pada awal pembelajaran. Revisi terhadap strategi pembelajaran dilakukan bila miskonsepsi yang muncul kembali bersifat sangat resisten. Hal ini penting dilakukan agar miskonsepsi tidak selamanya menghinggapi struktur kognitif, yang pada akhirnya akan bermuara pada kesulitan belajar dan rendahnya hasil belajar mahasiswa yang bersangkutan.

Hasil uji ANAVA faktorial 2x2 untuk menganalisis interaksi antara instructional model dengan entry level dalam meremidiasi miskonsepsi disajikan pada Tabel 1.

Tabel 1. Hasil Uji ANAVA Dependent Variabel: Miskonsepsi

\begin{tabular}{lrrrrr}
\hline \multicolumn{1}{c}{ Source } & $\begin{array}{c}\text { Type III Sum } \\
\text { of Squares }\end{array}$ & df & Mean Square & F & Sig. \\
\hline Corrected Model & $177.185^{\mathrm{a}}$ & 3 & 59.062 & 15.224 & .000 \\
Intercept & 4181.333 & 1 & 4181.333 & 1077.766 & .000 \\
EL & 100.148 & 1 & 100.148 & 25.814 & .000 \\
IM & 29.037 & 1 & 29.037 & 7.484 & .007 \\
EL * IM & 48.000 & 1 & 48.000 & 12.372 & .001 \\
Error & 403.481 & 104 & 3.880 & & \\
Total & 4762.000 & 108 & & & \\
Corrected Total & 580.667 & 107 & & & \\
\hline
\end{tabular}

a. R Squared $=.305$ (Adjusted R Squared $=.285$ )

Berdasarkan Tabel 1, dapat dirangkum sebagai berikut: (1) entry level berpengaruh signifikan terhadap remidiasi miskonsepsi $\quad(\mathrm{F}=25,814 ; \quad \mathrm{P}<0,05), \quad(2)$ instructional model berpengaruh signifikan terhadap remidiasi miskonsepsi ( $\mathrm{F}=7,484 ; \mathrm{P}<0,05)$, (3) terdapat interaksi antara entry level dengan instructional model dalam meremidiasi miskonsepsi $(\mathrm{F}=12,372 ; \mathrm{P}<0,05)$.

Pada pembelajaran konvensional, tenaga pendidik memfokuskan diri pada penuangan pengetahuan ke dalam diri mahasiswa, tanpa memperhatikan entry level peserta didik (transfer process). Di sisi lain, dalam model kooperatif, tenaga pendidik memusatkan perhatian pada pengkonstruksian makna pengetahuan dan berbasis entry level (transform process). Hasil penelitian menunjukkan bahwa antara tingkat entry level dan instructional model berinteraksi, dengan $\mathrm{F}=12,372$ dan signifikansi 0,001 . Hal ini menyatakan bahwa tingkat entry level dan instructional model menunjukkan profil interaksi. Perbedaan remidiasi miskonsepsi antara kedua kelompok mahasiswa (entry level tinggi dan rendah) karena pada kelompok mahasiswa yang mengikuti cooperative learning dan memiliki entry level tinggi terjadi proses transform secara utuh dan tuntas. 
Sedangkan dalam pembelajaran konvensional terjadi proses belajar dengan pola transfer, sehingga pemahaman konsep secara utuh lebih lambat terjadi. Bagi mahasiswa yang memiliki entry level rendah, lebih lambat terjadi proses pembelajaran bermakna, mengingat kelompok mahasiswa ini lebih lambat kemampuannya dalam hal mengakomodasikan konsep-konsep. Apabila kelompok mahasiswa yang memiliki entry level rendah mengikuti pembelajaran kooperatif dan model pembelajaran konvensional, maka remidiasi miskonsepsinya berbeda. Perbedaannya disebabkan karena pada kelompok mahasiswa yang mengikuti pembelajaran konvensional dan memiliki entry level rendah terjadi pemahaman yang utuh, yaitu melalui akomodasi konsep dari konsep yang bersifat formal menuju ke konsep yang bersifat konkret. Sebaliknya dalam pembelajaran koperatif dan entry level rendah, tetap terjadi proses transfer secara utuh, sehingga pemahaman tentang suatu konsep sifatnya hanya sementara. Dochy (1996) menyimpulkan bahwa pengetahuan awal berkontribusi signifikan terhadap skor-skor pascates. Menurut Dochy (1996), pembelajaran yang menggunakan pengetahuan awal sebagai starting point menunjukkan bahwa varians hasil belajar dapat dijelaskan oleh varians pengetahuan awal sebesar $42 \%$.

\section{KESIMPULAN DAN SARAN}

Pertama, profil miskonsepsi yang melekat pada diri peserta didik berkaitan dengan konsep-konsep dalam pembelajaran akuntansi cukup bervariasi dan terjadi pada pemahaman konsep kesatuan usaha (entity business concept), konsep harga perolehan (cost concept), dan konsep mempertemukan (matching concept). Kedua, tahapan-tahapan untuk mereduksi miskonsepsi secara efektif mulai dari tahapan orientasi, elicitasi, restrukturisasi, aplikasi, dan review.
Ketiga, Terdapat pengaruh interaktif antara instructional model dan entry level terhadap miskonsepsi mahasiswa.

\section{DAFTAR PUSTAKA}

Brooks, J. G., \& Brooks, M. G. (1993). In search of understanding: The case for constructivist classrooms. Virginia: Association for Supervision and Curriculum Development.

Dochy, F. J. R. C. (1996). Prior knowledge and learning. Dalam Corte, E.D., and Weinert, F. (eds.): International encyclopedia of developmental and instructional psychology. 456-467. New York: Pergamon.

Hailikari, T., Nevgi, A., \& Kamulainen, E. (2008). Academic self-beliefs and prior knowledge as predictors of student achievement in mathematics: A structual model. Educational Psychology: An International Journal of Experimental Educational Psychology, 28(1), 59-71.

Ikatan Akuntan Indonesia. (2012). Standar akuntansi keuangan (Cetakan pertama). Jakarta: IAI.

Kwon, J. (2006). The Effects of Cognitive Conflict on Students Conceptual Change in Physics. Journal of Physics Education Korean National University, 4(1), 64-79.

Lee, G. (2003). Development of An Instrument for Measuring Cognitive Conflict in Secondary-Level Science Classes. Journal of Research in Science teaching, 40(6), 585-603

Muhittin, C. (2014). Effect of cognitive entry behaviors and affective entry characteristics on learning level, 14 (5). doi:10.12738/estp.2014.5.1834. 
Mosik, M. P. (2010). Usaha mengurangi terjadinya miskonsepsi fisika melalui pembelajaran dengan pendekatan konflik kognitif. Jurnal Pendidikan Fisika Indonesia, 6, 98103.

Santoso, S. (2003). SPSS statistik multivariate. Jakarta: Elex Media Komputindo.

Santyasa, I. W. (2004). Pengaruh model dan seting pembelajaran terhadap remediasi miskonsepsi, pemahaman konsep, dan hasil belajar. (Disertasi Doktor, Universitas Negeri Malang, 2004).

Slavin, R. E. (1995). Cooperative Learning. Boston: Allyn and Bacon.

Suparno, P. (1997). Filsafat Konstruktivisme Dalam Pendidikan. Yogyakarta: Kanisius.

Thompson, R. A., \& Zamboanga, B. L. (2004). Academic aptitude and prior knowledge as predictors of student achievement in introduction to psychology. Journal of Educational Psychology, 96(4), 778-784. 